\title{
Philately Stamps on Heart
}

(Cardiovasc. j. 2013; 5(2): 208)

Heart is one of the popular topics for a philatelist. Many countries issued commemorative stamps and First Day Cover (FDC) on "Heart" In 1972, World Health Organization (WHO) observed its health day as "Good Heart Good Health". Different countries observed the occasion by issuing stamps depicting the theme on heart. In this region, India, Pakistan and Nepal issued stamps of heart at that time. Bangladesh, a new born country, did not issue any stamp on that occasion. On 12th September, 2012 the Hon'ble Prime Minister Sheikh Hasina formally inaugurated a set of stamp FDC and

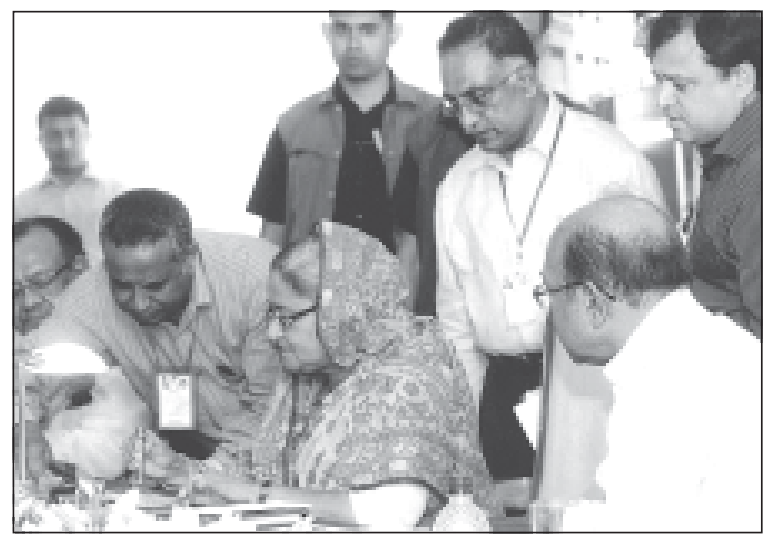

Inauguration of Stamp by Hon'ble Prime Minister Sheikh Hasina information sheet, which depict heart as the topic. The stamp and the FDC was issued by Bangladesh Post Office (in collaboration of National Institute of Cardiovascular Diseases, Dhaka, Bangladesh) to commemorate the $30^{\text {th }}$ anniversary of open heart surgery in Bangladesh. In 1981, First open heart surgery was done in NICVD i.e in Bangladesh.

Unique feature of the stamp are: (I) it is rombus shaped-first Bangladeshi stamp of this odd shape (II) It is first Bangladeshi stamp depicting Heart as a theme.

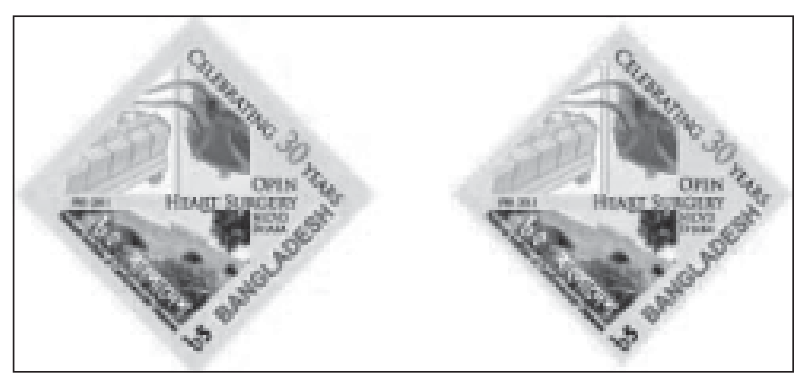

First Rombus shaped Bangladeshi stamp to commemorate $30^{\text {th }}$ anniversary of open heart surgery in Bangladesh

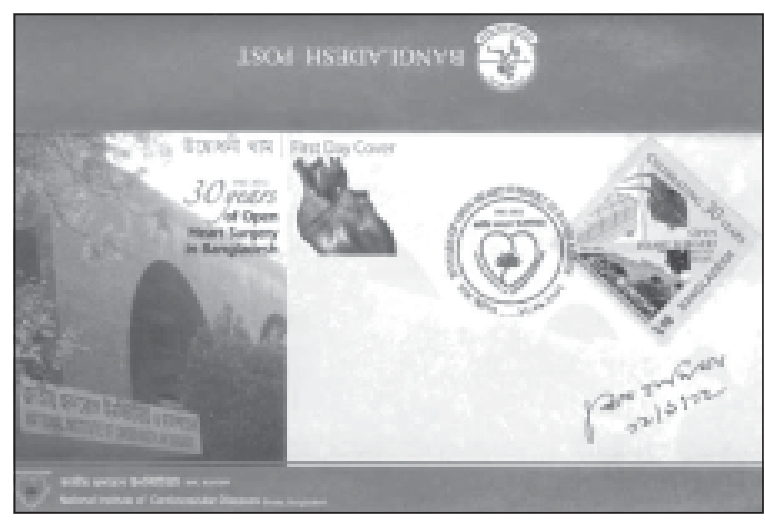

First Day Cover to commemorate $30^{\text {th }}$ anniversary of open heart surgery in Bangladesh 